\title{
Türkiye'de KOBİ'lerin Kazanç Yönetim Uygulamalarına Yönelik Muhasebe Meslek Mensuplarının Bakış Açıları Üzerine Bir Araştırma
}

\author{
Sedat ERDOĞAN* \\ Bilal SOLAK ${ }^{* *}$ \\ Seçkin GÖNEN ${ }^{* * *}$
}

\section{ÖZET}

Bu çalışmanın amacı Türkiye'de muhasebe meslek mensuplarının KOBI'lerin kazanç yönetim uygulamalarına dair görüşlerini incelemektedir. Bu kapsamda, Aydın, İzmir ve Malatya illerinde faaliyet gösteren muhasebe meslek mensuplarına anket yapılmıştır. Elde edilen sonuçlara göre katılımcıların yaklaşık\% 71 'i Türkiye'deki KOBI'lerin hem kar azaltıcı hem de kar artırıcı kazanç yönetim uygulamalarına başvurdukları tespit edilmiştir. Bu durum, literatürde belirtilen kazanç yönetim uygulamalarını destekler niteliktedir. Çalışmanın bulgularına göre vergi maliyetlerini düşürmek, kredi maliyetlerini düşürmek ve yatırımcıları çekmek kazanç yönetimin uygulama nedenleri olarak görülmektedir.

Anahtar Kelimeler: Kazanç Yönetimi, Yaratıcı Muhasebe, Muhasebe Meslek Mensubu, KOBİ, Türkiye.

JEL Sinıflandırması: M40, M41, M49.

\section{Perspectives of Accounting ProfessionalsTowards A Research on Earnings} Management Practices of SMEs in Turkey

\section{ABSTRACT}

This study investigates professional accountants' perspectives in terms of earnings management practices in Turkey. In this context, a survey application was administered to professional accountants in Aydin, Izmir, and Malatya. The results reveal that $71 \%$ of the participants believe SMEs apply both profit-reducing and profit-increasing earnings management techniques in Turkey. Among the most referenced reasons in the literature for earnings management; reducing tax expenses, reducing debt costs, and attracting investors are determined as three most important reasons for SMEs to apply earnings management techniques.

Keywords: Earnings Management, Creative Accounting, SMEs’Accounting Professionals, Turkey.

Jel Classification: M40, M41, M49.

\footnotetext{
* Sedat ERDOĞAN, Şırnak Üniversitesi İİBF İşletme Bölümü, sedaterdogan@sirnak.edu.tr

** Bilal SOLAK, Şırnak Üniversitesi İIBF İşletme Bölümü, bsolak@sirnak.edu.tr

*** Seçkin GÖNEN, Dokuz Eylül Üniversitesi İIBF İşletme Bölümü, seckingonen@hotmail.com
} 


\section{GİRIŞ}

Kazanç yönetim uygulamaları genel olarak firmalar ve yöneticileri tarafından, firmaların finansal tablolarından yer alan bilgilerin belli amaçlar etrafından, istenilen bir finansal görüntü elde etmek amacıyla muhasebe uygulamalarının tanıdığı esneklikler ve tercihler ışığında finansal bilgilerin yönetilmesini ifade etmektedir. Kazanç yönetim uygulamalarının yasal ve etik olup olmadığına ilişkin literatürde bir çok çalışma yapılmış olmasına karşın, araştırmacıların ve muhasebe meslek mensuplarının kazanç yönetim uygulamaları konusunda henüz mutlak bir görüş birliğinin oluşmadığı görülmektedir.

Kazanç yönetim uygulamalarının yapılabilir kılan etkenler incelendiğinde muhasebe mesleğinin yapısında kaynaklanan esneklikler olabileceği gibi ayrıca kazanç yönetim uygulamalarının ortaya çıkmasına etki eden en önemli unsurlardan birisi de bilgi asimetrisi olarak karşımıza çıkmaktadır. Çevik ve Erdoğan'a (2009) göre piyasadaki yatırımcılar daha az risk alarak daha yüksek getiri elde etmeye çalışmaktadırlar. Piyasa mükemmel değildir ve piyasadaki aktörler arasında bilgi farklılıkları vardır ve bu bilgi farklılı̆ı̆ sermaye maliyetinin artmasına neden olmaktadır. Bhattacharya ve Spiegel'e (1991) göre bilgi asimetrisi işlem kayıplarının ve yatırımcılar kendilerini potansiyel kayıplar karşısında korumak istediği için sermaye maliyetlerinin artmasina neden olabilmektedir.

$\mathrm{Bu}$ çalışma temel olarak kazanç yönetim uygulamalarının Türkiye'de muhasebe meslek mensupları tarafından nasıl görüldüğünü ortaya koymayı amaçlamaktadır. Bu kapsamda Türkiye'deki KOBİ'lerin kazanç yönetim uygulamalarına başvurup başvurmadığı KOBI'lere muhasebe hizmeti veren meslek mensuplarının görüşleri esas alınarak araştırılmıştır.

Çalışmada, veri toplama yöntemi olarak anket yöntemi belirlenmiştir. Malatya, İzmir ve Aydın illerinde faaliyette bulunan muhasebe meslek mensuplarına uygulanan anket yardımıyla veriler elde edilmiş̧ir. Anketlerin bir kısmı internet ortamında hazırlanmış anket formuyla ve diğer bir kısmı da muhasebe meslek odalarının yaptıkları toplantılarda yüz yüze anket formunun dağıtılmasıyla elde edilmiştir. Toplam 191 meslek mensubu çalışmaya katılmıştır ve bu örneklem yüzde 5 hata payı ile istatistiksel olarak 5 000- 10000 arasındaki ana kütleyi temsil etmektedir. Veri analizi için STATA 14 Veri Analizi ve İstatistiksel Yazılım Programı kullanılmıştır.

Bu kapsamda, çalışmada öncelikle muhasebe meslek mensuplarının Türkiye'de kazanç yönetim uygulamalarının yapılıp yapılmadığına dair görüşleri elde edilmeye çalışılmıştır. Kazanç yönetim uygulamalarının hem karları azaltıcı hem de karları artıııı kazanç yönetim uygulamaları şeklinde gerçekleştiği için katılımcıların her iki kazanç yönetim şekli için görüşleri esas alınmıştır. Kazanç yönetim uygulamalarının yapıldığını söyleyen muhasebe meslek mensuplarının kazanç yönetim uygulamaların hangi alanlarda yapıldıklarını cevaplamaları istenmiştir Böylelikle meslek mensuplarının bakış açısıyla kazanç yönetim uygulamalarının Türkiye'de KOBİ'ler tarafından daha ziyade hangi amaçlarla yapıldıkları 
incelenmiş olup, aynı zamanda da, katılımcıların demografik özelliklerinin (yaş, cinsiyet ve tecrübe vb.) kazanç yönetim uygulamalarına dair görüşleri üzerindeki istatistiksel etkileri olup olmadığı incelenmiştir. Gruplar arasındaki karşılaştırmayı sağlamak için parametrik olmayan ve iki veya daha fazla grubun meydanlarını karşılaştırarak gruplar arasındaki farklılıkları inceleyen Kruskal-Wallis Testi uygulanmıştır.

Çalışmanın birinci bölümünde kazanç yönetim uygulamaları ve yaratıcı muhasebe arasındaki ilişki incelenmiş olup kazanç yönetim kavramı ayrıntılı bir yapılış nedenleri esas alınarak açıklanmıştır. İkinci bölümde firmaların ve yöneticilerin kazanç yönetim uygulamalarına başvurma nedenleri, dünyada bu alanda çalışan bilim adamları tarafından elde edilen sonuçlar 1şığında, incelenmiştir. Üçüncü bölüm ise uygulama bölümüdür ve Türkiye'deki KOBİ'lerin kazanç yönetim uygulamaları yapıp yapmadıklarına dair tutumlarının muhasebe meslek mensuplarının bakış açısıyla incelenmesini içermektedir.

\section{YARATICI MUHASEBE VE KAZANÇ YÖNETIMİ}

Bağımsız denetim açısından yaratıcı muhasebe uygulamaları, mesleğin karşılaştı̆̆ı en ciddi problemlerden birisi olarak durmaktadır. Bu tür uygulamaların tespiti zor olduğu gibi çoğu zaman da var olan yasal boşluklar ve standartlardaki farklı yorum neticesinde gözden kaçabilmektedirler. Yaratıcı muhasebe uygulamalarıyla ilgili diğer bir sorunsa, karşılaşılan durumların çözümüne dair kafa karışıklığının olmasıdır. Hile kapsamında değerlendirilmeyen bu uygulamaların açıklanmasında uygulayıcıların niyetleri dikkate alınmaktadır. Niyetlerin taşıdığı öznellik, ileride yaşanabilecek finansal skandallara zemin hazırlayabilmektedir (Erdoğan, 2015:18-19).

Yaratıcı muhasebe uygulamalarının alt yapısı incelendiğinde, onlara genellikle yöneticilerin belli amaçlar için kullandıkları bir araç setidir denebilir. Shah ve Butt (2011) yaratıcı muhasebe uygulamalarının iç hedefleri tutturmak için, dışarıdakilerin şirket yönetiminden beklentilerini karşılamak için, gelir düzleştirici etkisinden dolayı, vergi amaçlı ve yine halka arzlarda ve kredi kullanımında bazı önemli durumları gizlemek için kullanıldığını vurgulamaktadırlar.

Mulford ve Comiskey'e (2002) göre kazanç yönetim uygulamaları, kazançların yönetim tarafından daha önceden belirlenen hedefleri karşılamak, genellikle daha istikrarlı ve sürdürülebilir kazanç oluşturmak maksadıyla, için yapılan kazançların aktif manipülasyonunu içerir. Yaratıcı muhasebe uygulamaları ise daha geniş bir biçimde finansal rakam oyunu yapmak için uygulanan tüm agresif uygulamaları, hileli finansal raporlamayı, kazanç yönetim ve gelir düzleştirme uygulamalarını içermektedir. Dolayısıyla kazanç yönetimi, yaratıcı muhasebenin bir bölümü olarak ifade edilmektedir. Öyle ki bu bölüm çoğu zaman yaratıcı muhasebe uygulamalarının yerine kullanılabilmektedir.

Jones'a (2011) göre yaratıcı muhasebe uygulamaları denince sadece kazanç yönetim uygulamaları değil ilişkili diğer kavramlar da akla gelmektedir. Bu kavramlardan en bilinenleri, agresif muhasebe, etki yönetimi, ve gelir düzleştirmedir. Yaratıcı muhasebe 
kavramı genellikle Avrupa'da kullanılmasına karşın, kavram Amerika'da genellikle kazanç yönetimi olarak kullanılmaktadır (Rajput, 2014:194). Yaratıcı muhasebeyi finansal muhasebe bilgilerinin aslında oldukları durumdan var olan belli standart ya da kurallardaki eksikliklerden yararlanarak ya da onları kısmen ya da tamamen yok sayarak yapılan dönüştürme sürecidir (Naser, 1993:272). Aslında buradaki temel mesele muhasebe standartlarının ve politikalarının işletmelerde yapılan tüm işlemleri tam bir bütünlük halinde kavramasının büyük ölçüde mümkün olamamasından kaynaklanmaktadır (Shahvd, 2011: 533).

Kazanç yönetimi uygulamalarının değerlendirilmesinde dikkat edilmesi gereken diğer bir husus ise bu uygulamalarla hile arasındaki ilişkidir. Dechow ve Skinner (2000: 239-240) hile ve kazanç yönetimi arasındaki farkı ifade ederken yapılan işlemin Genel Kabul Görmüş Muhasebe İlkelerine göre yapılıp yapılmadığını esas almaktadır. Bu ilkelere göre yapılmayan uygulamaları hileli kabul etmekte ve bu ilkelere göre yapılanları ise yapılan eylemin niyetini içerecek şekilde tekrar dikkate almaktadır. Yani bu ilkelere göre yapılan eylemlerde firmanın gerçek ekonomik performansı üzerinde bir maskeleme yapılıp yapılmadığı ve yöneticilerin önceden belirlenmiş nedenlerle bu uygulamaları yapıp yapmadıkları dikkate alınmalıdır.

\section{KAZANÇ YÖNETIM UYGULAMALARININ TEMEL NEDENLERİ}

Mulford ve Comiskey (2002) firma yöneticilerinin kazanç yönetim uygulamalarının altında yatan sebepleri genel olarak dört başlık halinde vermektedirler: Hisse senedi fiyatları üzerindeki etkiler, borçlanma maliyetleri, yönetici ücret ve teşvikleri üzerindeki etkiler ve politik maliyetler. Tablo 1 bu kategorileri ve yapılan kazanç yönetim uygulamalardan yöneticilerin beklentilerini vermektedir.

Tablo 1: Kazanç Yönetim Uygulama Yöntemleri ve Kazanımları

\begin{tabular}{ll}
\hline Kategori & Kazanımlar \\
\hline Hisse Senedi Fiyatları Üzerindeki Etkiler & Hisse senedi fiyatlarını yükseltmek \\
& Hisse senedi volatilitesini düşürmek \\
& Kurumsal değeri artırmak \\
& Özsermaye maliyetini düşürmek \\
Borçlanma Maliyetleri & Hisse senedi opsiyonlarının değerini artırmak \\
& Kredi kalitesini artırmak \\
& Borçlanma derecesini artırmak \\
& Borçlanma maliyetlerini azaltmak \\
Bonus Planları Üzerindeki Etkiler (Yönetici Ücret ve & Sözleşmelerin yumuşatılması \\
Teşvikleri) & Kara dayalı teşvikleri yükseltmek \\
Politik Maliyetler & \\
& Yasal Düzenlemelerin azaltılması \\
& Yüksek vergilerin azaltılması \\
\hline
\end{tabular}

Kaynak: Mulford, W. Charles, ve Comisken, E. Eugene, 2002, The Financial Numbers Game: Detecting Creative Accounting Practices, John Wiley\&Sons, Inc. New York. 
Mulford ve Comiskey (2002) tarafından yukarıda yapılan sınıflandırma incelendiğinde kazanç yönetim uygulamalarıyla ilgili üç temel neden karşımıza çıkmaktadır. Bunlar; yatırımcı çekmek (özellikle hisse senetleri fiyatlarını artırmak suretiyle), borçlanma maliyetlerini düşürmek ve vergi yükünü hafifletmektir.

\subsection{Yatırımcı Çekmek}

Kazanç yönetimiyle ilgili yapılan çalışmalarda, özellikle Amerika'da ve sermaye piyasaları gelişmiş olan ülkelerde, şirketlerin piyasa değeri ile kazanç yönetimi arasındaki ilişkinin sıklıkla incelendiği görülmektedir. Bu durumun altında yatan sebeplerden biri olarak bu ülkelerde çok fazla halka açı şirket yer alması ve şirketlerin hisse senetlerinin geniş bir alana yayılmış olması gösterilebilmektedir. Sermaye piyasası gelişmekte olan ülkelerde ise genellikle yatırımcı çekmek maksadıyla benzer uygulamaların yapıldığı tespit edilmiştir.

Dechow ve Skinner'a (2000:248) göre kazanç yönetim uygulamalarına başvurulma nedenlerini anlamak için yöneticilerin çıkarlarını iyi analiz etmek gerekmektedir. Özellikle finansal analistlerin beklentilerini karşılamak için yöneticiler tarafından çoğu zaman kazanç yönetim uygulamaları yapıldığı gözlenmektedir. Cormier vd. (2015) ise İsviçre’de yöneticilerin kar payları üzerinde kazanç yönetim uygulamaları yaptıkları ve daha yüksek kar payı almak için muhasebe tercihlerini zorladıklarını gözlemişlerdir.

Watts ve Zimmerman (1978:113) sözleşmeye bağlı sonuçları etkilemek için yöneticilerin isteğe bağlı davranışları ile kazanç raporlamak suretiyle kazanç yönetim uygulamalarına başvurdukları ve hatta kendi refahlarını artırmak için firmaların kaynaklarını standartları oluşturanların fikirlerini değiştirmek için kullandıklarını tespit etmişlerdir.

Kazanç yönetim uygulamalarının tespitinden birçok farklı model (Ör. Beneish (1999)) kullanılmış olmasına karşın literatürde özellikle ihtiyari tahakkukların kullanılmasına odaklanıldığı görülmekte ve ihtiyari tahakkukların hesaplanması için bir çok farklı model (Ör. Healy (1985; Jones (1991)) kurulduğu görülmektedir (Dechow vd.1995:194).

Bergstresser ve Philippon (2006) tahakkukların yüksek olduğu yıllarda CEO'ların oldukça yüksek opsiyon hakkı kullandıkları ve içeriden öğrenenlerin ise yüksek oranda hisse senedi sattıklarını görmüşlerdir. Yani birçok firma kazanç yönetim uygulamalarıyla teşviklerini artırdıklarını göstermektedir. Cheng ve Warfield (2005) ise yöneticilerin ellerindeki teşvikleri olabildiği kadar yüksek fiyattan satma niyetinde olduklarını ve bu niyetleri gerçekleştirmek için ise kazanç yönetim uygulamalarından faydalandıkları tespit etmişlerdir.

Healy ve Wahlen (1999) göre kazanç yönetimi yöneticilerin finansal raporlamaya ilişkin yargılarda bulunduklarında veya bazı paydaşları firmanın gerçek ekonomik performansına dair yanıltmak ya da finansal tablolarda elde edilen bilgilere bağlı olarak sözleşmeye bağlı sonuçları etkilemek için muhasebe işlemlerinin finansal raporlamayı değiştirecek şekilde yapılandırılmasıyla oluşturduklarını ifade etmişılerdir. 


\subsection{Borçlanma Maliyetlerini Düşürmek}

Firmalar daha düşük maliyetle borçlanma imkânları varken daha yüksek borçlanma maliyetinden kaçınma eğiliminde olacaklardır. Özellikle yöneticilerin firmaların durumlarını olduğundan çok daha iyi bir durumda gösterme eğilimleriyle karşılaşıldığında kazanç yönetim uygulamaları karşımıza çıkabilmektedir. Yapılan birçok çalışma firmaların borçlanma maliyetlerini düşürmek için kazanç yönetim uygulamalarına başvurduklarını göstermektedir.

Moreira ve Pope (2007) firmaların kayıpla kapattıkları yıllarda kazanç yönetim uygulamaları daha fazla uygulamak suretiyle bu kayıpların piyasada firmaların kredi maliyetleri üzerindeki etkisinin gizlemek istediklerini tespit etmişlerdir. Öyle ki daha yüksek borçlanma gereği duyan firmaların borçlanma maliyetlerini düşürmek için daha fazla kazanç yönetim uygulamaları yaptıkları tespit etmişlerdir

Sweeney (1994) muhasebe esnekliklerini ve vergi maliyetleriyle ilgili mevcut muhasebe değişimlerini incelediği çalışmasında, yöneticilerin borçlanma maliyetinden kaçabilmek için kazanç yönetimi uyguladıklarını görülmüştür. Özellikle borçlanma sözleşmesine aykırı durumlarla karşılaşıldığında gelir artırıcı muhasebe politika tercihlerinin yapıldığı görülmektedir. DeFond ve Jiambalvo (1994) borç sözleşmesi ihlalinden bir yıl önce gelir artırıcı anormal tahakkuklar anormal bir şekilde arttığını görmüşlerdir.

DeAngelo vd. (1994) ise finansal sıkıntıya düşmüş firmaların yöneticilerinin kazançları artırmayacağı ve firmayı daha az sorunlu gibi göstermeyeceği, bunun yerine negatif anormal tahakkuklar suretiyle firmayı olduğundan daha kötü göstereceğini böylelikle de borçlanma sözleşmesine taraf olanlarla yeniden pazarlık aşamasına geldiğinde daha iyi sonuçlar alınabileceğini belirtmiştir. Jaggi ve Lee (2002) DeAngelo vd. (1994) tarafından elde edilen sonuçları bir adım daha ileri götürerek, finansal sıkıntıya düşmüş firmaların yöneticilerinin borç sözleşmesi ihlaline dair krediyi veren firmadan istisna/muafiyet alabiliyorsa gelir artırıcı kazanç yönetim uygulamalarına başvurduklarını, aksine böyle bir istisna/muafiyet söz konusu değilse, yeniden pazarlık aşaması için gelir azaltıcı kazanç yönetim uygulamalarına başvurduklarını tespit etmişlerdir.

\subsection{Vergi Maliyetini Düşürmek}

Firmalar ödedikleri vergiyi azaltmak maksadıyla kazanç yönetim uygulamaların başvurabilmektedir (Phillips vd., 2003). Özellikle vergi yükünün ağır olduğu ülkelerde, firmalar ve yöneticiler bu maliyetleri düşürmek için kazanç yönetim uygulamalarına başvurabildikleri görülmektedir. Badertscher vd. (2006) kazanç yönetim uygulamalarının raporlanmış kazançları artırmak ya da azaltmak maksadıyla yapılıp yapılmadığına bakılmaksızın, firmaların vergi maliyetlerini azaltmak için kazançlarını yönettiklerini tespit etmişlerdir.

Wang ve Chen (2012) Çin'deki halka açık anonim şirketlere yönelik olarak yaptıkları çalışmada vergiden kaçınmayı amaç edinen kazanç yönetim uygulamalarının sıklıkla 
uygulandığını tespit etmişlerdir. Kazanç yönetimi uygulamaları ile vergiden kaçınma arasında güçlü korelasyon olduğunu tespit etmişlerdir.

\section{4. ÇALIŞMANIN AMACI VE KAPSAMI}

Bu çalışmada Türkiye'de muhasebe meslek mensuplarının Türkiye'deki KOBİ'lerin kazanç yönetim uygulamalarına başvurup başvurmadıklarına dair görüşleri incelenerek sonuçlar yorumlanmıştır. Katılımcıların KOBİlerin kazanç yönetim uygulamalarına başvurup başvurmadıklarına dair görüşleri elde edildikten sonra, Türkiye'deki KOBİ'ler kazançlarını yönetiyordur diyen katılımcıların, kendi tecrübelerini dikkate alarak hangi tür kazançların en çok yönetildiğini ifade etmeleri istenmiştir. Böylelikle uygulamacı bakış açısıyla KOBİ'lerin kazanç yönetim uygulamalarına başvurma nedenleri incelenmiştir.

Büyük işletmelerin ve KOBİ'lerin kazanç yönetim uygulamaları çoğu zaman birbirinden farklı şekilde gerçekleştiği düşünülmektedir. Büyük işletmelerin genellikle piyasa değerleri üzerinde kazanç yönetim uygulamaları yaptıkları yukarıda incelenmiştir. KOBİ'lerin sahip oldukları yapıları itibariyle daha küçük firmalar oldukları ve finansal tablolarında yer alan finansal bilgilerin genellikle firma dışındaki muhasebeciler tarafından hazırlandıkları göz önünde bulundurulduğunda, kazanç yönetim uygulamalarına başvurma sıklıkları kullanılan ekonometrik modellerle değil de hizmeti veren muhasebecilerin bakış açıları dikkate alınarak incelenmesinin daha sağlıklı bilgiler vereceği düşünülmüş ve bu kapsamda hazırlanmış bir anket yardımıyla görüşleri elde edilmiştir. Veri analizinde STATA 14 Veri Analizi ve İstatistiksel Yazılım Programı kullanılmıştır.

\section{1. Çalışmanın Metodolojisi}

Araştırmada veri toplama yöntemi olarak anket yöntemi kullanılmıştır. Anket yöntemi, göz atım araştırmalarında en önemli bilgi toplama aracı olup, cevaplayıcılardan bilgi toplamak için biçimlendirilmiş bilgi formlarıdır (Nakip, 2006:119). Anket uygulaması Malatya, İzmir ve Aydın illerinde bağımsız faaliyet gösteren muhasebe meslek mensuplarına uygulanmıştır.

\begin{tabular}{|l|l|l|}
\hline Meslek mensubunun bağlı olduğu il & Bağımsız olarak çalışan meslek mensubu & $\begin{array}{l}\text { Ankete katılmayı kabul eden meslek } \\
\text { mensubu }\end{array}$ \\
\hline Malatya & 396 & 61 \\
\hline Aydın & 368 & 101 \\
\hline İzmir & 5.028 & 29 \\
\hline Toplam & 5.792 & 191 \\
\hline
\end{tabular}

Çalışma kapsamında elde edilen örneklem sayısı olan 191 Yazıcığlu ve Erdoğan (2004) tarafından belirtilen 5.000-10.000 arasındaki evrenler için yüzde 5 hata payı ile kabul edilebilir nitelikte olduğu tespit edilmiştir.

Çalışmanın planlanması aşamasında Şırnak ve Mardin illeri de araştırma kapsamına alınmasına karşın, bölgede yaşanan olumsuz durumlar nedeniyle bu illerde sağlıklı veri elde 
edilememiş ve çalışmanın kapsamı dışında bırakılmışlardır. Katılımcıların demografi özelliklerine ilişkin dağılımlar Tablo 2'de gösterilmektedir.

Tablo 2: Ankete Katılan Meslek Mensuplarına Ait Demografik Özellikler

\begin{tabular}{|c|c|}
\hline Cinsiyet & Gözlem Sayısı \\
\hline Kadın & 45 \\
\hline Erkek & 146 \\
\hline Bağlı Bulunan Mesleki Oda & Gözlem Sayısı \\
\hline Malatya & 61 \\
\hline İzmir & 29 \\
\hline Aydin & 101 \\
\hline Yaş & Gözlem Sayısı \\
\hline $23-30$ & 18 \\
\hline $31-37$ & 55 \\
\hline $38-45$ & 59 \\
\hline $46-53$ & 37 \\
\hline 53 ve üstü & 22 \\
\hline Tecrübe & Gözlem Sayısı \\
\hline $0-5$ & 18 \\
\hline $6-11$ & 44 \\
\hline $12-17$ & 50 \\
\hline $18-23$ & 49 \\
\hline 23 ve üstü & 30 \\
\hline İşletme Türü & Gözlem Sayısı \\
\hline Ulusal & 181 \\
\hline Uluslararası & 10 \\
\hline Mezuniyet & Gözlem Sayısı \\
\hline YMM & 0 \\
\hline SMMM & 176 \\
\hline SMMM+Bağımsız Denetçi & 15 \\
\hline
\end{tabular}

\section{2. Çalışmanın Yöntemi ve Veri Analizi}

Kullanılan ölçme aracında bütün soruların birbiriyle tutarlılığını ve ele alınan oluşumu ölçmede türdeşliğin (homojenlik) olup olmadığını tespit etmek amacı ile (Özdamar, 2002) güvenilirlik analizi yapılmış ve bu amaçla geliştirilmiş çeşitli yöntemler bulunmasına karşın çalışmamızda Cronbach Alfa katsayısı kullanılmıştır. Cronbach Alfa katsayısının istatistik temelleri tutarlı ve tüm soruları dikkate alarak hesaplandığından genel güvenirlik yapısını en iyi yansıtan istatistiki bir yöntemdir (Özdamar, 2002). Cronbach Alfa katsayısı şu şekilde değerlendirilir: 0-0.4 güvenir değil, 0.4-0.6 düşük güvenirlik, 0.6-0.8 oldukça güvenilir, 0.81.0 yüksek güvenirlik(Alpar, 2003). Çalışmamızda, Cronbach's Alpha değeri ortalama 
\%83.22 olarak gerçekleşmiştir. Değişkenlere ilişsin elde edilen Cronbach's Alpha değerleri \%81-\%87 arasında değişmektedir. Dolayısıyla elde edilen verilerin iç tutarlılığının yüksek olduğu ifade edilebilir. Anket sorularının normal dağılım gösterip göstermediklerine yönelik normallik testi uygulanmış olup, analize göre değerlerin -1.5 ile +1 arasında olduğu görülmüştür. George ve Mallery, (2010) göre değerlerin +2.0 -2.0 arasında olması normal dağılım sağlandığı görüşündedirler.

Çalışmaya katılan katılımcıların Türkiye'deki KOBİ'lerin kazanç yönetim uygulamaları yapıp yapmadıklarına dair görüşleri incelendiğinde katılımcıların \%71'i Türkiye'de KOBİ'lerin kazanç yönetim uygulamalarına başvurduklarını ve katılımcıların \%29'u ise Türkiye'deki KOBİ'lerin kazanç yönetim uygulamalarına başvurmadıklarını ifade etmektedir. Yani katılımcıların yaklaşık 4'te 3'ü Türkiye'de faaliyette bulunan KOBİ'lerin bir şekilde (kar artırıcı ya da kar azaltıcı) kazanç yönetim uygulamaları kullandıklarına inanmaktadırlar.

Tablo 3: Katılımcıların Türkiye'deki KOBİ'lerin Kazanç Yönetim Uygulaması/Uygulamaları Yapıp Yapmadığına Dair Görüşleri

\begin{tabular}{lllll}
\hline Görüș & Gözlem Sayısı & Oran & Standart Sapma & \%95 Güven Aralığı \\
\hline Hayır & 55 & 0.2879 & 0.03285 & $0.2231-0.3527$ \\
Evet & 136 & 0.7121 & 0.03285 & $0.6472-0.7768$ \\
\hline
\end{tabular}

Araştırmanın birinci bölümünde muhasebe meslek mensuplarının Türkiye'de KOBI'lerin kazanç yönetim uygulamalarına dair görüşleri ile katılımcıların demografik özellikleri arasında bir ilişkinin var olup olmadığı incelenmek istenmiştir. Bu kapsamda uygun test seçim aşamasında verilerin özellikleri dikkate alınarak uygun test seçimi yapılmaya çalışılmıştır.

Parametrik testlerin uygulanabilmesi için verilerin normal dağılıma uyması gerekmektedir. Verilerin normalliğinin sınanmasında sıkça kullanılan testlerden birisi olan ve örneklemin aynı dağılımdan çekilip çekilmediğin test eden Kolmogorov-Smirnov (K-S) testi kullanılmıştır. Araştırma verilerine yapılan Kolmogorov-Smirnov (K-S) test sonuçlarına göre verilerin normal dağılıma uymadığı $(0,05<$ p) görülmüştür. Parametrik olmayan testlerde verilerin normal dağılıma uyması gerekmediğinden çalışma kapsamında elde edilen veriler parametrik olmayan testlerle sınanmıştır.

Tek yönlü varyans analizinin parametrik olmayan alternatifi olan Kruskal-Wallis analizi sürekli değişkenlere sahip üç ya da daha fazla grup arasında karşılaştırma yapma imkanı sağlamaktadır. Test aynı zamanda da ikiden fazla grubun farklı olup olmadığını anlamak için grupların medyanlarını karşılaştırmaktadır (Rumsey, 2007:295).

$$
H=\frac{12}{N(N+1)} \sum_{\mathrm{i}=1}^{C} \frac{R i^{2}}{n_{i}}-3(N+1)
$$


Denklemde (1)'de C örneklerin sayısını, $n_{i}$ gözlem sayısını, $N=\sum n i$ tüm örneklerin toplam gözlem sayısını ve $R i$ ise i’inci örneğin sıralamalarının toplamını vermektedir.

Kruskal-Wallis testinin arkasında yatan temel mantık, ilgili her bir guruptan örnekler toplayarak, ilgili verilerin küçükten büyüğe doğru sıralanması ve bu sıralamanın çeşitli örneklerde nasıl dağıldığıyla ilgili bir ilişki aranmasıdır. Bir örnek tüm küçük değerleri ve bir diğeri de tüm yüksek değerleri alıyorsa bu durum bize medyanların farklı olduğuna işaret edebilmektedir. Diğer yandan tüm örnekler aynı ölçüde küçük ve yüksek değerler alıyorsa bu durum medyanlar arasında bir farklılık olmadığı anlamına gelmektedir (Rumsey, 2007:295). Sıralama yoluyla yapılan istatistiksel analizlerde, parametrik testlerdeki gibi birçok varsayımın sağlanması gerekmemektedir. Verilerin birbirinden bağımsız olması analize tabi tutulabilmeleri açısından yeterlidir (Kruskal ve Wallis, 1952: 586).

Uygulamaya katılan meslek mensuplarının demografik özelliklerinin (yaş, cinsiyet, mesleki tecrübe vb.) KOBİ'lerin kazanç yönetim uygulamaları üzerinde bir etkiye sahip olup olmadığını belirlemek için Kruskal-Wallis testleri yapılmıştır (Örneğin katılımcıların cinsiyetlerinin kazanç yönetim uygulamalarına dair görüşleri üzerinde istatistiksel anlamlı bir etkisinin olup olmadığının incelenmesi.). Tüm demografik özelliklere ilişkin test sonuçları Tablo 4'te verilmektedir.

Elde edilen Kruskal-Wallis test sonuçlarına göre, Türkiye'deki KOBİ'lerin kazanç yönetim uygulamalarına başvurup başvurmadığına dair katılımcı görüşleri üzerinde, bağlı bulundukları meslek odalarının, cinsiyetlerinin, yaşlarının, tecrübe düzeylerinin, muhasebesini üstlendikleri firmaların türlerinin, mezuniyetlerinin ve unvanlarının istatistiksel anlamlı bir etkisinin olmadığı görülmektedir. Elde edilen sonuçlar Tablo 4'te raporlanmıştır.

Tablo 4:Kazanç Yönetim Uygulaması Yapılıp Yapılmadığına İlişkin Katılımcı Görüşlerine Dair Kruskal Wallis Test Sonuçları

\begin{tabular}{lll}
\hline Bağıı Bulunan Meslek Odası & Gözlem Sayısı & Sıra Toplamı \\
\hline Malatya & 61 & 100.01 \\
\hline İzmir & 29 & 107.03 \\
\hline Aydın & 101 & 90.41 \\
Ki-Kare & & 4.083 \\
Olasılık & & 0.1298 \\
Cinsiyet & Gözlem Sayısı & Sıra Toplamı \\
\hline Kadın & 45 & 87.42 \\
\hline Erkek & 146 & 98.64 \\
Ki-Kare & & 2.304 \\
\hline Olasılık & & 0.129 \\
Yaş & Gözlem Sayısı & Sıra Toplamı \\
\hline
\end{tabular}




\begin{tabular}{|c|c|c|}
\hline $23-30$ & 18 & 96.97 \\
\hline $31-37$ & 55 & 104.40 \\
\hline $38-45$ & 59 & 91.13 \\
\hline $46-53$ & 37 & 87.36 \\
\hline 53 ve üstü & 22 & 101.80 \\
\hline Ki-Kare & & 4.679 \\
\hline Olasılık & & 0.3218 \\
\hline Tecrübe & Gözlem Sayısı & Sira Toplamı \\
\hline $0-5$ & 18 & 102.27 \\
\hline $6-11$ & 44 & 97.45 \\
\hline $12-17$ & 50 & 94.85 \\
\hline $18-23$ & 49 & 100.11 \\
\hline 23 ve üstü & 30 & 85.30 \\
\hline Ki-Kare & & 2.73 \\
\hline Olasılık & & 0.604 \\
\hline İşletme Türü & Gözlem Sayısı & Sira Toplamı \\
\hline Ulusal & 181 & 95.54 \\
\hline Uluslararası & 10 & 104.40 \\
\hline Ki-Kare & & 0.396 \\
\hline Olasılık & & 0.5291 \\
\hline Mezuniyet & Gözlem Sayısı & Sira Toplamı \\
\hline Lisans & 176 & 95.826 \\
\hline Yüksek Lisans & 14 & 96.21 \\
\hline Doktora & 1 & 123.5 \\
\hline Ki-Kare & & 0.405 \\
\hline Olasılık & & 0.8165 \\
\hline Ünvan & Gözlem Sayısı & Sira Toplamı \\
\hline YMM & 0 & 0 \\
\hline SMMM & 176 & 96.91 \\
\hline SMMM+Bağımsız Denetçi & 15 & 85.3 \\
\hline Ki-Kare & & 0.991 \\
\hline Olasılık & & 0.8165 \\
\hline
\end{tabular}

Türkiye'de KOBİ'ler kazanç yönetim uygulamalarına başvuruyor düşüncesine sahip olan katılımcılara, bu kazanç yönetim uygulamalarının karı azaltıcı mı yoksa artırıcı mı olduğu sorulduğunda, tüm katılımcılar her iki tür kazanç yönetim uygulamalarının da yapıldı̆̆ı görüşüne sahip oldukları görülmüştür.

Kazanç yönetimi alanında çalışan araştırmacıların kazanç yönetiminin yapılma nedenlerini inceledikleri çalışmaları dikkate incelenmiş ve en çok kazanç yönetimine başvurulma nedenleri belirlenmiş ve katılımcılara sorulmuştur. Katılımcılara aynı zamanda da anket formunda yer almayan fakat kendilerinin önemli olduğunu düşündükleri farklı kazanç 
yönetim uygulamalarını belirtmeleri için yer bırakılmışıı. Fakat katılımcılar tarafından farklı bir kazanç yönetim nedeni beyan edilmemiştir. Belirlenen ve katılımcılara sorulan kazanç yönetim nedenleri şu şekildedir:

Karı Azaltıcı Kazanç Yönetim Uygulama Nedenleri

- Vergi maliyetini düşürmek,

- Kar payı dağıtım politikası (kar dağıtımı yapılmak istenmemesi durumu),

- $\quad$ Eski yönetimin kötü olduğunu göstermek için (yönetim devrinin alındığı yıl finansal tablolarını olduğundan çok daha kötü göstermek).

Karı Artırıcı Kazanç Yönetim Uygulama Nedenleri

- Yatırımcı çekmek,

- Kredi maliyetlerini düşürmek,

- Teşviklerden yararlanmak,

- Yeni ortak bulmak,

- Yurtdışına açılmak,

- Kar payı dağıtım politikası (kar dağıtımı yapmak istenmesi durumu),

Türkiye'de KOBİ'ler kazanç yönetim uygulamalarını kullanıyordur diyen katılımcıların kazanç yönetim uygulama nedenlerine ilişkin tanımlayıcı istatistikler Tablo 5'de ayrıntılı bir şekilde gösterilmektedir.

Tablo 5: Türkiye'de KOBİ'lerin Kazanç Yönetim Uygulama Nedenleri

\begin{tabular}{llllll}
\hline Değişkenler & $\begin{array}{l}\text { Gözlem } \\
\text { Sayısı }\end{array}$ & Ortalama & $\begin{array}{l}\text { Standart } \\
\text { Sapma }\end{array}$ & Minimum & Maksimum \\
\hline Karı Azaltıcı Kazanç Yönetim Uygulamaları & & & & \\
\hline Vergi Maliyetini Düşürmek & 136 & $\underline{\mathbf{7 . 5 0}}$ & 2.96648 & 1 & 10 \\
\hline Kar Dağııım Politikası & 136 & 4.18 & 2.88342 & 1 & 10 \\
\hline Eski Yönetimi Kötü Göstermek & 136 & 3.23 & 2.33482 & 1 & 10 \\
\hline Karı Artırıcı Kazanç Yönetim Uygulamaları & & & & \\
Yatırımcı çekmek & 136 & $\underline{\mathbf{5 . 2 5}}$ & 3.04716 & 1 & 10 \\
Kredi Maliyetlerini Düşürmek & 136 & $\underline{\mathbf{6 . 5 7}}$ & 2.9255 & 1 & 10 \\
Teşviklerden Yararlanmak & 136 & 4.58 & 2.97285 & 1 & 10 \\
\hline Yeni Ortak Bulmak & 136 & 4.32 & 2.90308 & 1 & 10 \\
\hline Yurt Dışına Açılmak & 136 & 4.33 & 2.94657 & 1 & 10 \\
\hline Kar payı Dağıtım Politikası & 138 & 4.12 & 2.77581 & 1 & 10 \\
\hline
\end{tabular}

Elde edilen veriler ışığında Türkiye'deki KOBI'lerin kazanç yönetim uygulamalarına dair meslek mensuplarının görüşleri dikkate alındığında, karı azaltıcı kazanç yönetim uygulamalarının temel olarak vergi maliyetini düşürmek için yapıldığı ve karı artırıcı kazanç yönetim uygulamalarının ise özellikle kredi maliyetlerini düşürmek ve yatırımcı çekmek amaçlarıyla yapıldığı görülmektedir. 
Elde edilen sonuçlar aslında kazanç yönetiminin uygulamalarını araştıran araştırmacılar tarafindan elde edilen sonuçlarla örtüşmektedir. Yani kazanç yönetim uygulamaları eğer karı azaltıcı kazanç yönetim uygulaması şeklinde gerçekleşiyorsa temel olarak vergi maliyetlerini düşürmek amacıyla gerçekleştirilmektedir. Zira, katılımcıların \%50'si kazanç yönetim uygulamalarının vergi amaçlı yapıldığına maksimum puan olan 10 puanını vermişlerdir. Aksi durumda, yani karı artırıcı kazanç yönetim uygulamaları yapılıyorsa bunun temel iki nedeni olarak borçlanma maliyetini düşürmek ve firmanın yatırımcılar tarafindan daha cazip bir finansal durum oluşturulması amaçları ön plana çıkmaktadır.

Türkiye'deki KOBİ'lerin kazanç yönetim nedenleri olarak belirtilen bu üç nedene ilişkin katılımcıların demografik özelliklerinin görüşleri üzerindeki etkisi incelendiğinde, bazı demografik özelliklerin katılımcıların kazanç yönetim uygulamaları KOBİ'ler tarafından vergi maliyetlerini düşürmek ve kredi maliyetlerini düşürmek için yapılmaktadır görüşleri üzerinde istatistiksel anlamlı bir etkisinin olduğu tespit edilmesine karşın, kazanç yönetim uygulamaları KOBI'ler tarafından yatırımcı çekmek için yapılıyordur görüşüne sahip olan katılımcıların görüşleri üzerinde demografik özelliklerinin hiçbir istatistiksel anlamlı bir etkiye sahip olmadığı görülmüştür. Bu kapsamda, ilişki bulunan tüm demografik özelliklere ilişkin sonuçlar Tablo 6' da raporlanmıştır.

Tablo 6: Vergi Maliyetlerini Düşürme İle Katılımcı Özelliklerine Dair Kruskal-Wallis Test Sonuçlar

\begin{tabular}{|c|c|c|c|}
\hline & & Vergi Maliyetlerini Düşürmek & $\begin{array}{l}\text { Kredi Maliyetlerini } \\
\text { Düşürmek }\end{array}$ \\
\hline Bağlı Bulunan Mesleki Oda & Gözlem Sayısı & Sıra Ortalaması & Sira Ortalaması \\
\hline Malatya & 46 & 70.72 & 57.96 \\
\hline İzmir & 24 & 49.21 & 58.58 \\
\hline Aydın & 66 & 73.95 & 79.44 \\
\hline Ki-Kare & & 8.252 & 10.157 \\
\hline Olasılık & & 0.016 & 0.006 \\
\hline Cinsiyet & Gözlem Sayısı & Sira Ortalaması & Sira Ortalaması \\
\hline Kadın & 28 & 55.61 & \\
\hline Erkek & 108 & 71.84 & \\
\hline Ki-Kare & & 4.354 & \\
\hline Olasılık & & 0.037 & \\
\hline Yaş & Gözlem Sayısı & Sıra Ortalaması & Sira Ortalaması \\
\hline 23-30 & 13 & 49.88 & 64.85 \\
\hline 31-37 & 44 & 68.83 & 49.16 \\
\hline 38-45 & 39 & 57.08 & 66.81 \\
\hline $46-53$ & 23 & 79.30 & 86.22 \\
\hline 53 ve üstü & 17 & 93.47 & 101.26 \\
\hline
\end{tabular}




\begin{tabular}{llll}
\hline Ki-Kare & & 17.001 & 27.892 \\
\hline Olasılık & Gözlem SayıSI & Sira Ortalaması & 0.000 \\
\hline Tecrübe & 14 & 43.29 & Sira Ortalaması \\
$\mathbf{0 - 5}$ & 32 & 80.52 & 51.46 \\
$\mathbf{6 - 1 1}$ & 35 & 58.57 & 57.41 \\
$\mathbf{1 2 - 1 7}$ & 37 & 67.01 & 65.73 \\
$\mathbf{1 8 - 2 3}$ & 18 & 89.11 & 83.27 \\
$\mathbf{2 3}$ ve üstü & & 18.350 & 76.50 \\
\hline Ki-Kare & & 0.001 & 11.559 \\
Olasilık & & & 0.021 \\
\hline
\end{tabular}

Tablo sonuçları incelendiğinde kazanç yönetim uygulamaları KOBİ'ler tarafindan vergi maliyetini düşürmek için yapılıyordur görüşü üzerinde bağlı bulunduğu meslek odasının, cinsiyetin, yaş ve tecrübenin istatistiksel anlamlı bir etkisin olduğu görülmektedir. Bu kapsamda İzmir'deki katılımcılara kıyasla Malatya ve Aydın'daki katılımcıların ve kadınlara kıyasla erkeklerin kazanç yönetim uygulamalarının vergi amaçlı yapıldığına istatistiksel anlamlı bir şekilde daha yüksek değerler verdiği görülmektedir. Yine aralarında yüksek korelasyon olan yaş ve tecrübe düzeylerinin de arttıç̧a kazanç yönetim uygulamalarının vergi amaçlı yapıldığına duyulan inançlarının arttığı tespit edilmiştir.

Kredi maliyetleri açısından incelendiğinde Aydın'daki katılımcıların diğer illerdeki katılımcılara kıyasla kazanç yönetim uygulamalarının kredi maliyetlerini düşürmek amacıyla yapıldığına daha çok inanmaktadırlar. Yine benzer bir sonuç olarak da yaş ve tecrübe düzeyi arttıkça kazanç yönetim uygulamalarının kredi maliyetlerini düşürmek amacıyla yapıldığına daha çok inanıldığı görülmektedir.

\section{SONUÇ}

Kazanç yönetim uygulamaları özellikle gelişmiş ülkelerde piyasa fiyatı üzerinde yapılmak suretiyle çoğu zaman temsil maliyetiyle ilişkilendirilen bir durum olarak karşımıza çıkmaktadır. Birçok çalışmada büyük işletmelerin kazanç yönetim uygulamaları incelenmesine karşın, KOBİ'lerin kazanç yönetim uygulamalarına literatürde pek rastlanmamaktadır. Türkiye gibi gelişmekte olan ülkeler açısından KOBİ'lerin ekonomideki önemi dikkate alındığında, bu çalışma kazanç yönetim uygulamalarının Türkiye'deki KOBI'ler tarafından uygulanıp uygulanmadığını ve eğer uygulanıyor ise hangi amaçlar için uygulandığını ortaya koymayı amaçlamaktadır.

Muhasebe meslek mensuplarının KOBİ'lerin kazanç yönetim uygulamalarının incelendiği bu çalışmada temel olarak iki dikkat çekici sonuç elde edilmiştir. Birinci önemli nokta meslek mensuplarının KOBİ'lerin kazanç yönetim uygulamaları yaptıklarına dair inançlarının oldukça yüksek olmasıdır. Katılımcıların yaklaşık 4'te 3'ü, KOBİ'lerin bir şekilde kazanç yönetim uygulamalarından yararlandığını ortaya koymaktadır. Bu kapsamda, 
KOBI'lerin hem kazanç artırıcı hem de kazanç azaltıcı kazanç yönetim uygulamalarıyla belli bir amaç için finansal tablolarını yönettikleri görülmektedir. İkinci önemli nokta ise, Türkiye'de KOBİ'lerin vergi maliyetlerini düşürmek için kazanç azaltıcı kazanç yönetim uygulamalarına başvurdukları ve yatırımcı çekmek ve kredi maliyetlerini düşürmek için ise kazanç artırıcı kazanç yönetim uygulamalarından yararlandıkları tespit edilmiştir.

Başlangıçta bu çalışmanın 5 ili kapsaması ve bölgeler arasındaki farklılıkları da ortaya çıkarması planlanmasına karşın, Şırnak ve Mardin illerinde sağlıklı veriye ulaşım imkanının bulunmaması nedeniyle Aydın, İzmir ve Malatya illeriyle sınırlandırılmıştır. İller arasında KOBI'lerin kazanç yönetim uygulamalarına dair meslek mensuplarının beklentileri açısından istatistiksel anlamlı bir farklılık elde edilmemiş olmasına karşın, araştırma sahasının genişletilmesiyle bölgeler arasındaki farklılıkların incelenebileceği ve KOBI'lerin sektörel olarak farklı kazanç yönetim uygulamalarının olup olmadığı da ileriki araştırmalara konu edinebilir.

\section{KAYNAKLAR}

ALPAR, Reha, (2003), Uygulamalı Çok Değişkenli İstatistiksel Yöntemlere Giriş I, 2. Bask1, Nobel Yayınevi, Ankara

BADERTSCHER, Brad- Phillips, JOHN -Pincus Morton- REGA, S. Olhoft, (2006) Do Firms Manage Earnings Downward in a BookTaxConformingManner?,http://www.worldlii.org/int/journals/lsn/abstracts/921422.ht ml.

BENEISH, D. Messod, (1999), “The Detection of Earnings Manipulation”, Financial Analysts Journal, Vol: 55, No:5, pp. 24-36.

BERGSTRESSER, Daniel ve THOMAS, Philippon (2006), “CEO Incentivesand Earnings Management”, Journal of Financial Economics, 80(3), pp.511-529.

BHATTACHARYA, Utpal, - SPIELGEL, Matthew, (1991), “Insiders, Outsiders, and Market Breakdowns”, The Review of Financial Studies, 4(2), pp.255-282.

CHENG, Qiang, - WARFIELD, D. Terry, (2005), "Equity Incentivesand Earnings Management”, The Accounting Review, 80(2), pp.441-476.

CORMIER, Denis- MAGNAN, Michel - MORARD, Bernard (2000), “The Contractual and Value Relevance of Reported Earnings in a Dividend-Focused Environment”, The European Accounting Review, 9(3), pp.387-417.

ÇEVİK, E. İsmail - ERDOĞAN, Sedat (2009), "Bankacılık Sektörü Hisse Senedi Piyasası Etkinliği: Yapısal Kırılma ve Güçlü Hafıza”, Doğuş Üniversitesi Dergisi, 10 (1), ss.26-40.

DECHOW, M. Patricia ve SKINNER, J. Douglas (2000), Earnings Management: Reconcilingthe Views of Accounting Academics, Practitioners, and Regulators, “Accounting Horizons”, 14(2), pp.235-250 
DECHOW, M. Patricia -SLOAN, G. Richard.- SWEENEY, P. Amy, (1995), "Detecting Earnings Management”, The Accounting Review, 70(2), pp.193-225.

ERDOĞAN, Sedat (2015), "Finansal Skandalların Bağımsız Denetim Boyutu”, Mali Çözüm, Say1. 128, ss.14-32.

GEORGE, Darren - MALLERY, Paul (2010), SPSS for Windows Step by Step: A Simple Guide and Reference, 17.0 update (10a ed.) Boston: Pearson

HEALY, M. Paul - WAHLEN, M. James (1999), "A Review of theEarnings Management Literature and its Implications for Standard Setting”, Accounting Horizons, 13(4), pp.365-383.

HEALY, P. M. (19859, “The Effect of Bonus Schemes on Accounting Decision”, Journal of Accounting and Economics, 7, pp. 85-107

JAGGI, Bikki - LEE, Picheng (2002), "Earnings Management Response to Debt Covenant Violations and Debt Restructuring”, Journal of Accounting, Auditing and Finance, 17(4), pp.295-324.

JONES, J. (1991), “Earnings Management During Important Relief Investigation”, Journal of Acounting Research, 29, pp. 193-228.

JONES, Michael (2011), Creative Accounting, Fraudand International Accounting Scandals, John Wiley and Sons, West Sussex, England

KRUSKAL, H. William - WALLIS W. Allen (1952), "Use of Ranks in OneCriterionVariance Analysis", Journal of theAmerican Statistical Association, Cilt 47, Say1 260, pp. 583-621.

MOREIRA, A.C. Jose - POPE, F. Peter (2007), "Earnings Management toAvoid Losses: A Cost Of Bebt Explanation”, DP 2007-04, Research Center on Industrial, Labourand Managerial Economics, pp.1-45.

MULFORD, W. Charles - COMISKEN, E. Eugene, (2002), The Financial Numbers Game: Detecting Creative Accounting Practices, John Wiley\&Sons, Inc. New York.

NAKIP Mahir, (2006), Pazarlama Araştırmaları Teknikler ve (SPSS Destekli) Uygulamalar, 2.Baskı, Seçkin Kitapevi: Ankara

ÖZDAMAR, Kazım, (2002), Paket Programlar ile İstatistiksel Veri Analizi-I, SPSSMINITAB, 4. Baskı, Kaan Kitabevi, Eskişehir.

PHILLIPS, John - PINCUS, Morton - REGO S. Olhoft (2003), "Earnings Management: New Evidence Based on Deferred Tax Expense”, The Accounting Review, 78(2), pp. 491521.

RAJPUT, M. Singh (2014), “Creative Accounting: Some Aspects”, International Journal of Business and Administration Research Review, Vol.2, No.4, pp.193-199.

RUMSEY, Deborah (2007); Intermediate Statistics for Dummies, John Wileyand Sons, USA. 
SHAH S. Z. Ali- SAFDAR Butt - YASIR Bin Tariq (2011), "Use or Abuse of Creative Accounting Techniques”, “International Journal of Trade, Economicsand Finance, Vol. 2, No. 6, pp. 531-536.

SHAH, S. Z. Ali - SAFDAR Butt (2011), “Creative Accounting: A Toolto Help Companies in a Crisisor a Practiceto Land Theminto Crises”, 2011 International Conference on Business and Economics Research, IPEDR Vol. 16, pp. 96-102.

SWEENEY, A. Patricia, (1994), "Debt-covenant Violationsand Managers Accounting Responses”, Journal of Accounting and Economics, 17, pp.281-308.

WANG, Shiwei - CHEN, Siyu, (2012), “The Motivation for Tax Avoidance in Earnings Management”, 2012 International Conference on Engineeringand Business Management, pp. 447-450.

WATTS, L. Ross - ZIMMERMAN, L. Jerold, (1978), "Towards a Positive Theory of the Determination of Accounting Standards”, The Accounting Review, 53(1), pp. 112134.

YAZICIOĞLU, Yahşi - ERDOĞAN, Samiye (2004). Spss Uygulamalı Bilimsel Araştırma Yöntemleri, Ankara:Detay Yayıncılık. 
